\title{
Beyond Virtual Carnival and Masquerade
}

\section{In-Game Marriage on the Chinese Internet}

\author{
Weihua $\mathrm{Wu}$ \\ New York University \\ Steve Fore \\ City University of Hong Kong \\ Xiying Wang \\ Petula Sik Ying Ho \\ Hong Kong University
}

\begin{abstract}
This article documents the brief history of cyber marriage on the Chinese Internet and shows how in-game marriage, with its game codes and marriage regulations, turns out to be the most visualized, institutionalized, and heteronormative form of cyber marriage, by exploring the game players' gender performativity, especially the gender swapping of male gamers. This study sheds light on Chinese youth subculture under the influence of new media and the consumer digital network in postsocialist China.
\end{abstract}

Keywords: cyber marriage; MMORPG; performativity; gender swapping; youth subculture; computer-mediated communication

\section{"Marriage Bells Toll in the Cyber Church"}

The year 2001 witnessed the coining of the Internet neologism "cyber marriage" (in Chinese, wanghun ${ }^{1}$ ) by Internet users (Liu, 2002). This term refers to the virtualmarriage-making activity that is mostly conducted on the Internet and remains there. As of 2005, more than 120,000 cyber marriages have been registered online according to Chinese Women (Zhen, 2001), News Weekly (J. Li, 2004), and Youth Reference (Feng, 2004). ${ }^{2}$ In-game marriage spontaneously emerged from the popularity of cyber marriage, in the span of the past 6 years, with the boosting of Internet-based

\footnotetext{
Authors' Note: The research on which this paper is based was supported by the International Center for Advanced Studies at New York University and the School of Graduate Studies at City University of Hong Kong. An early version was presented at the International Conference of Heteronormativity: A Fruitful Concept, sponsored by The Overseas Research Funding and the Conference Grand, City University of Hong Kong. This research also benefited from the helpful suggestions of ICAS' fellows and the anonymous journal reviewers.
} 
Table 1

Numbers and Percentages of Chinese Online Game Players and MMORPG Players, 2001-2004

\begin{tabular}{lcc}
\hline & Online Game Players (millions) & $\begin{array}{c}\text { MMORPG player (percentage } \\
\text { of all online game players) }\end{array}$ \\
\hline 2001 & 4.95 & $2.18(44.2)$ \\
2002 & 9.50 & $4.14(43.6)$ \\
2003 & 12.95 & $6.53(50.04)$ \\
2004 & 19.76 & $8.71(44.1)$ \\
\hline
\end{tabular}

Source: Shanghai iResearch Co. (2004).

Note: $\mathrm{MMORPG}=$ massively multiplayer online role-playing game.

computer games, particularly those in which game players simulate and articulate narrated images of virtual-marriage lives with others in the gaming scenario brought on by massively multiplayer online role-playing games (MMORPGs). Its vanguards (the traditional text-based cyber marriage, such as BBS marriage, QQ wedding, ${ }^{3}$ and chat-room marriage) lacked in-game marriage's distinctive characteristics, including more undergaze visuality and an overt heterosexual bias of computer-mediated relationships. By focusing on the gaming context of the MMORPGs and related Internet surroundings, this study attempts to open a space for understanding Chinese in-game marriage and the youth cultural context emerging from its playful circumstances by offering a profile of Chinese young people performing their own responses to digitalized gender, sexuality, and socially resonant issues of heteronormativity involved in both daily gaming activities and playful carnival and masquerade that accompany them.

Since 2000, the Chinese computer game industry has benefited from the following two developments: One is the government's recent development strategy and the establishment of state-sponsored animation bases nationwide, and the other is the investment of overseas computer game companies (Zhang, 2005). In the past, computer gaming survived only as a subcultural activity in the blind points of government censorship and was ignored by the mainstream media. Now it has become one of the most important domains that the government nurtures, in particular with a view to investing in the huge potential of the Chinese game market. A survey of Internet use by the China Internet Network Information Center (CNNIC, 2005) ${ }^{4}$ shows that more than $19.76 \%$ out of 94 million Chinese Internet users had been involved in online game entertainments by the end of December 2004; another report shows that 168 Chinese-language massively multiplayer online games (Chen, 2004) were launched by domestic computer game companies before August 2004, among which 33.18\% were MMORPGs (Shanghai iResearch Co. \& 17173.com., 2004). According to iResearch's China Online Game Research Report 2004, board games and MMORPGs together boasted about $60 \%$ of gamer coverage in 2004, and about $44.1 \%$ of gamers played MMORPGs most frequently (Shanghai iResearch Co., 2004). 
Table 2

Timing of Involvement in, and Percentage of, Online Gaming for All Chinese Internet Users

\begin{tabular}{lc}
\hline When Players Started Playing Online Games & $\begin{array}{c}\text { MMORPG player (percentage of all } \\
\text { Chinese Internet users) }\end{array}$ \\
\hline Before 2000 & 16.7 \\
2000 & 31.3 \\
2001 & 10.8 \\
2002 & 13.2 \\
2003 & 11.4 \\
2004 & 8.2 \\
2005 & 6.5 \\
2006 (until July) & 1.9 \\
\hline
\end{tabular}

Note: $\mathrm{MMORPG}=$ massively multiplayer online role-playing game.

As Tables 1 and 2 show, MMORPGs have become one of the most popular forms of entertainment among Chinese young people, and the heated growth and popularity of MMORPGs are expected to continue (Xu \& Tian, 2005; J. Zhang, 2005; Zhen, 2005).

Domestic MMORPG services, such as Netease.com and Kingsoft Corp., have developed massive resources through which millions of gamers will have access to play. With interactive gaming storytelling, upload screenshots, writing down personal feelings and gaming experiences in the Broad Bulletin System (BBS), gamers' particular Blogs, and semiofficial online journals, these extended spaces nurtured by MMORPG gaming activities create a relatively liberal communicative platform for young people to experience interactive entertainment with animated features and filmic story lines. Moreover, they offer possibilities for ongoing integration between the Internet and everyday life of the general public (Bakardjieva \& Smith, 2001; Bargh, 2002; DiMaggion, Hargittai, Neuman, \& Robinson, 2001; Howard \& Jones, 2004; Wellman \& Haythornthwaite, 2002). For example, the Web sites of Easy Blogger (xiaoyao ke), hosted by Kingsoft Corp. at http://blog.xoyo.com/, encourage gamers to exchange gaming experiences with each other by blogging their virtual lives. Some relevant Web sites such as Easy Show (xiaoyao xiu) at http://show.xoyo .com/ have offered services for gamers to upload personal photos and gaming snapshots. By August 28, 2006, Easy Show had around 42,872 registered users, with 18,304 albums of photos including around 113,725 images, ${ }^{5}$ including photos from both gamers' real lives and gaming snapshots.

The gaming space of MMORPGs has now extended beyond digital leisure activity. It is not only reconstructed within the socioeconomic order under postsocialist state discourse but has also become a notable example to show how use of the internet has gradually influenced changing relationships among Chinese young peoplethe latter having especially been brought about and highlighted by the boosted popularity of MMORPG-related cyber marriage. 
The everyday practice of in-game marriage does provide a new perspective on the forms of computer-mediated relationships and proposes a new framework, that of Chinese Internet ethnography, for understanding the attitudes and behaviors of young Chinese people regarding gender, sexuality, and daily life. The adventure of in-game relationships and the emotional interactions with other gamers represent a striking mapping of contemporary Chinese youth subculture, which struggles to find its own voice between the commercial digital environment and ideological surveillance in postsocialist society. Here we attempt to answer questions of how game players give meaning to the in-game marriage and how they perform gender through it. We also aim to examine how gamers' practices of in-game marriage contribute to challenging gender stereotypes, hierarchy, and heteronormativity, both on the Internet and in reality.

This study conducts a textual analysis based on participant observation carried out from January 2005 to August 2006 to look at the regulations of in-game marriage systems of the most popular MMORPGs listed in the Top 10 registered-users MMORPGs of $2004,{ }^{6}$ with special attention paid to the official Web sites and BBS hosted on the game developer's servers (particularly on Swordsmen Online, Fantasy Westward Journey, and Westward Journey II). The first author interviewed 15 game players (seven women and eight men) in March 2005. These semistructured interviews (usually around 1 hour each) were conducted online through two popular Internet Relay Chat (IRC) software programs: MSN and ISQ (same as ICQ, but only available for Chinese Mac users). The ages of these game players ranged from 20 to 28, and all of them had been playing MMORPGs for more than 2 years. Nine of them had experienced in-game marriage at least once, and all others had attended ingame weddings online. All quotations included in this article have been translated into English by the authors, and all names mentioned herein are pseudonyms. The first author conducted a follow-up study between July and August 2006 by mainly focusing on collections of government reports, Internet surveys, and cyber-marriage events broadcast on Chinese media.

\section{The Visualized World of In-Game Marriage}

Following text-based cyber marriages and structures of narrative of Multi-User Dungeon or Dimension (MUD) games, in-game marriage first appeared as an extra emotional bonus of the game reward system, in addition to virtual money and treasures, in the MMORPGs.

The earliest form of cyber marriage was the text-based cyber marriage, which still exists and is quite popular on the present-day Chinese Internet. Figure 1 demonstrates the cyber marriage certificate issued by Sohu Community. It usually involves getting married in online communities or chat rooms by typing set vows of marriage. The procedure of the text-based cyber marriage is very simple. Both potential spouses send messages to ask the wangguan's (forum organizer's) permission to get married. After being approved and getting married successfully, the operator of the 


\section{Figure 1 \\ Marriage Certificate for Text-Based Cyber \\ Marriage of Sohu Community}

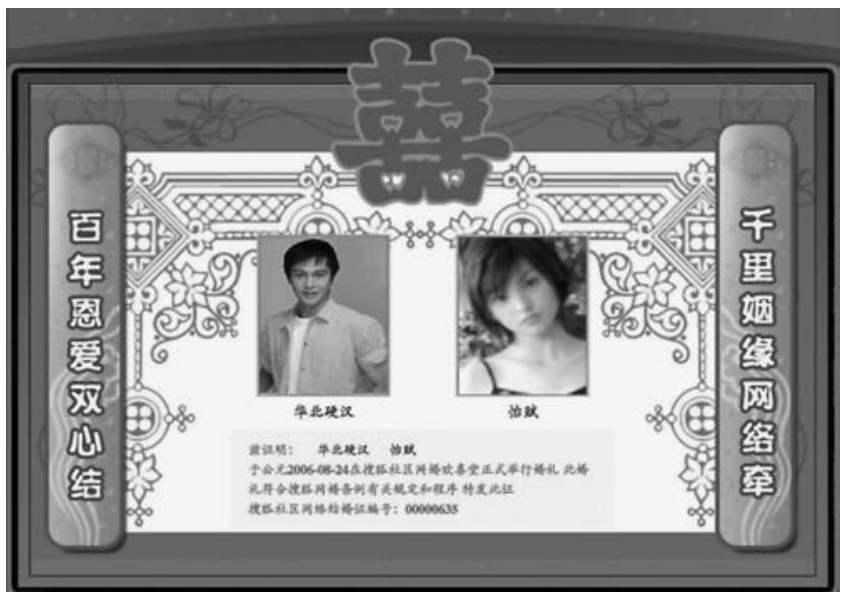

Note: Marriage certificate for Huabei Yinghan (literally, his name means "tough man from Northern China") and Yibin (literally, "sweet and nice"). The wedding service in Sohu Community Cyber-Marriage Happiness Hall on August 24, 2006. This marriage is legitimate according to the Sohu cyber-marriage laws. Sohu Community Cyber-Marriage certificate No. 00000635.

cyber marriage-serving Web sites will send the couple greeting mail, host the virtual wedding, and issue a marriage certificate for public access. The couple's marriage names will be listed in the virtual community daily. Following the launch of its cyber-marriage system in "Sohu Community" in April 2004, sohu.com, one of the most popular mass portals in Mainland China, ceremonialized 304 heterosexual couples and 8 homosexual couples in cyber marriage by August 28, 2006.

Another type of cyber marriage that needs to be mentioned is its performance in the MUD games, which involves

[a] loosely binding agreement between two players to behave within a game as if they are married. Usually established with a formal ceremony (whatever that means in the specific game) attended by high ranking members of the game administration. Sometimes couples are afforded additional rights, such as having a private domain or house. A record of the marriages is generally publicized. (McDaniel, 1993)

Chinese in-game marriage otherwise visualizes cultural uniqueness with regard to the issue of a computer-mediated relationship and text-based cyber marriage in some particular ways. The avatars in the text-based cyber marriage have been taken over by the in-game marriages avatars, which are visualized and visibly gendered animated 
two- or three-dimensional bodies. Danet (1996) and Graddol and Swann (1989) proposed that avatars in text-based cyber marriage contribute to digitalized gender equality, thus perhaps making the situation more democratic, in a playful way. However, as we take a second look at the 8 homosexual marriages (compared with 304 heterosexual ones) during the past 2 years in Sohu Community, we see that such imagined equality has been overtly challenged and repressed by the visualized gendered bodies in the MMORPG-related cyber marriage. Compared with the simple procedure of text-based cyber marriage, in-game marriage is complicated and is dominated by heterosexual ideology and gender-biased gaze because of the systematic regulations of how to get married in the games. Meanwhile, in-game marriage defines itself in a commodified context ${ }^{7}$ that articulates the cultural imperialism of commercial entertainment (Kücklich, 2003) that is particularly benefited by state-sponsored policy and overseas computer-gaming enterprises and develops individualism by personal gaming (Cherny, 1999; Ducheneaut \& Moore, 2004) instead of disappearing into a morass of digital cultural conformity.

Cyber marriage constructs a flourishing picture of the self-adventure of Chinese young people on the internet and becomes one of the representative events in what is called "the third sexual revolution" in P. R. China (Huang, 2002). It mocks the heaviness of normative marriage and the legitimacy of contract relationships by introducing an image of digital ethnography that is practiced and experienced by millions of Chinese to pursue alternative dating and marital life on the Internet, either seriously or just playfully. According to primary Web site organizer Lazhuo at Tianya Wedding Hall, by July 2006, this Wedding Hall, launched in 2001 at Tianya Community, had issued 1,156 cyber-marriage certificates, involving 14 couples who developed relationships in reality and finally got married in reality (although 239 cyber-married couples had got cyber divorces).

However, the mainstream discourse criticizes that the phenomenon of cyber marriage "has encroached on social ethics and even violates the law" (Jiang, 2005; Zhou, 2004) by leading young people to misunderstand marriage.

Some people call it the danger zone. They believe that cyber marriage is innocuous as long as it is kept in cyberspace. But once you have the yen to bring it into the realm of reality, you will risk jeopardizing your above-board marriage. (Zhou, 2004)

In the past few years, there have been many cases involving game players or Internet users in legal disputes concerning cyber marriages that have been considered to have destroyed real-life marriages. Usually, innocent husbands and wives suddenly find that their spouses have engaged in other marriages on the Internet, having virtual sex or even giving birth to virtual babies (e.g., in Fantasy Westward Journey), and then go to court and ask for a divorce (Dai \& Li, 2004; Fang, 2004; Wang \& Gao, 2004). ${ }^{9}$ Most existing Chinese studies of MMORPGs focus on the negative outcomes of gaming (such as 


\section{Figure 2}

\section{Marriage Certificate for In-Game Marriage of Swordsman Online II}

Note: Marriage certificate for Shaxuecan'ai (male) and Wushuang yanzhi (female). The 18th district 4th server. This certificate was issued on May 18, 2006 to both spouses. Notice for all men: The woman Wushuang yanzhi now belongs to Shaxuecan'ai, who owns himself. Notice for all women: This man Shaxuecan'ai now belongs to Wushuang Yanzhi, who owns herself.

aggressive behavior, addiction, social isolation, and identity confusion [He \& Liu, 2005; $\mathrm{H}$. Li, 2004; Lu, 2004]) of players, rather than viewing it as an activity that forms an important part of many people's leisure lifestyles (Bryce \& Rutter, 2003). However, in this study, these game players are viewed as individuals with strong mobility, flexibility, and the spirit of adventure rather than as victims passively influenced by gaming.

Among the 2004 Top 10 domestic MMORPGs, 8 have detailed marriage systems, whereas the other 2 do not have any yet, mainly because of system limitations and the lack of gaming modules for operating in-game marriage. More and more Chinese MMORPGs form the in-game marriage certificates intimately initiated from within the institutionalized rituals of the Chinese society today. Figure 2 demonstrates the finalized visual format of the in-game marriage certificate, symbolically linked the individual players with each other, and with the industrialized collectivity of Chinese computer game by the "contract relationship." Most Chinese-language MMORPGs nostalgically link with ethnic folk culture and social context and usually anchor storylines in traditional Chinese novels such as Journey to the West (xiyouji) and Romance of the Three Kingdoms (sanguo yanyi) by following the classical narrative structure of heterosexual love stories that involve the following sequence: "birth of 


\section{Figure 3}

\section{Fairy-Tale Wedding—Bridegroom's Vowing}

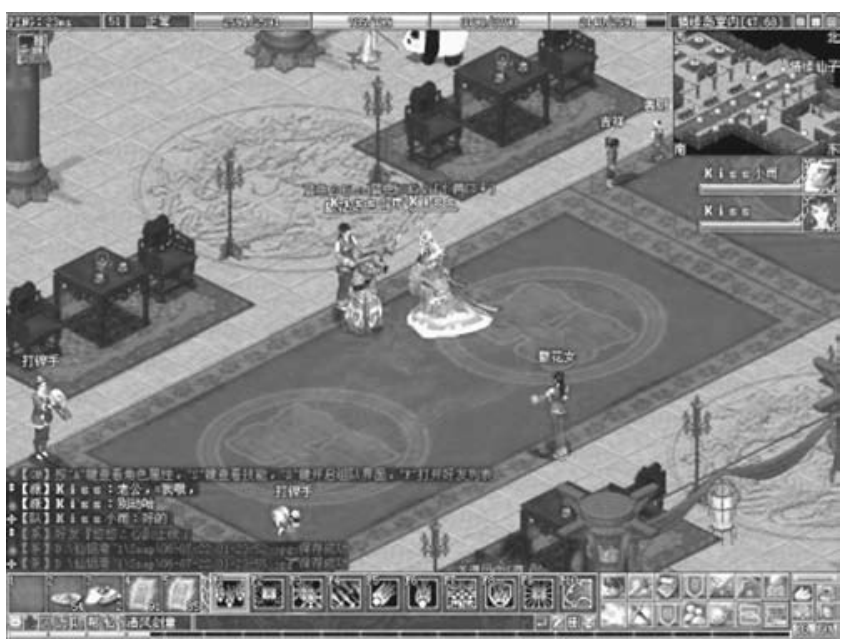

Note: Uploaded by Benyu'er (literally, Silly Rain) on June 22, 2006 from http://show.xoyo.com, Swordsmen Online.

\section{Figure 4}

\section{Fairy-Tale Wedding —Celebrating After the Wedding Ceremony}

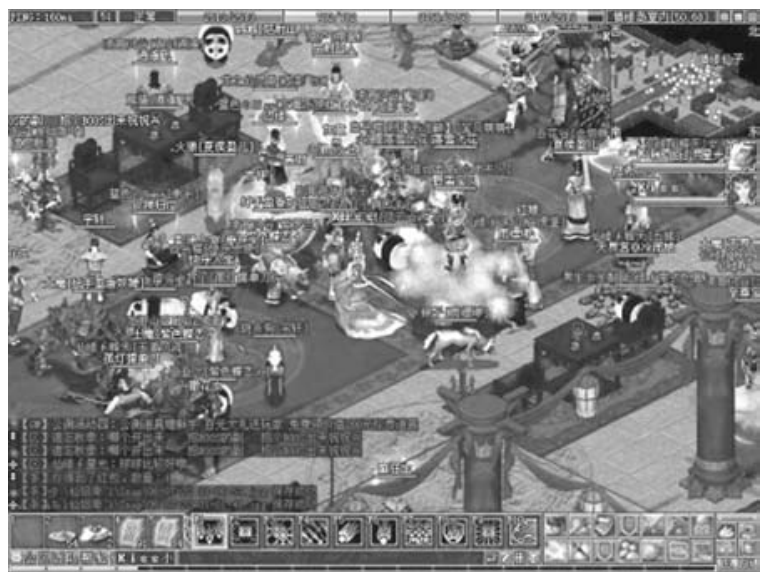

Note: Uploaded by Benyu'er (literally, Silly Rain) on June 22, 2006 from http://show.xoyo.com, Swordsmen Online. 


\section{Figure 5}

\section{Wedding and Honeymoon}

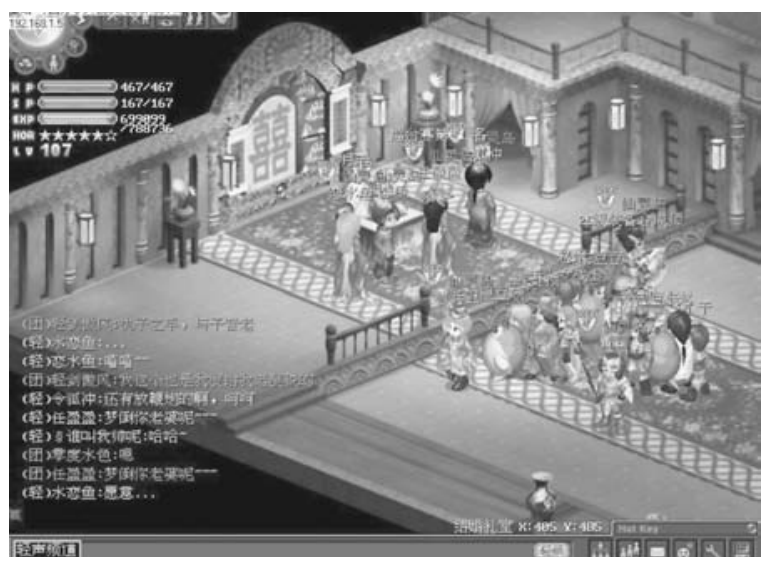

Note: This wedding takes place on a fairy island called Xianling Island, where three couples have a group ceremony today. Uploaded by Yu'er'cui (literally, Fish Wind) on March 7, 2004, from http://jinyong .jygamebbs.com.

the hero" (players create an avatar), "meeting the princess" (two players let their online avatars fall in love with each other), and "hero getting married" (two players decide to let their online avatars get married). All these steps correspond with the assumptions of a typical narrative and imply heterosexual ideas. Because happy endings are a part of heteronormative storytelling, game players are required to follow the typical marriage instructions from Chinese folk and ethnic traditions. (See Figures 3-4.) The nostalgic visuality and ethnic imaginaries derived from the past Confucian history are necessary elements of in-game marriage for game codes of most of Chinese MMORPGs. The sequences of in-game marriage images in Figures 5-11 demonstrate the procedure of a particular heterosexual wedding coded through the traditional Chinese symbols of red lantern, shuangxi (double happiness), ancient golden nuggets, and garden. In the case of Swordsmen Online, there are five criteria that players need to work on before proposing an in-game marriage. They are the following: (a) A man and a woman should be grouped in a gaming team; (b) the fiancé should be the team leader; (c) both are required to be at least at the 20th level; (d) neither are temporary members of Shaolin or E'mei, which means neither monks nor nuns are included; (d) during the game in progress, none can leave the team, go offline, or travel outside of Jiangjin, where the in-game marriage-authorizing institution 
Figure 6

Wedding and Honeymoon

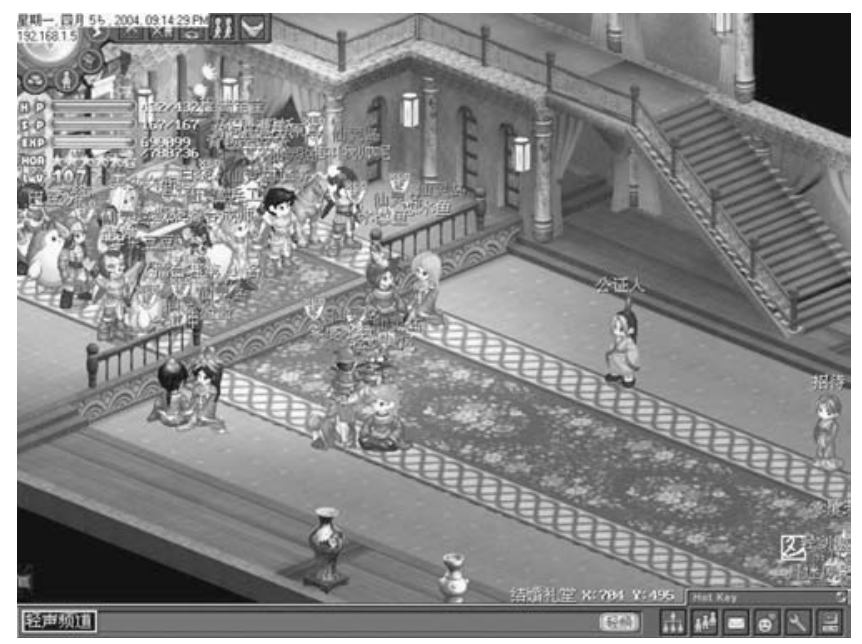

Note: Three couples are wating for the marriage host. Uploaded by Yu'er'cui (literally, Fish Wind) on March 7, 2004, at http://jinyong.jygamebbs.com.

is located. These criteria are samples of basic information about regulations, rules, and marriage laws enacted within different Chinese-language MMORPGs and bear striking similarities and implications that resonate with Chinese social norms and rituals. The sequences of wedding images in Figures 12-17 show the particular Chinese folk rituals, which require that bride and bridegroom should vow to Heaven and Earth, and sometimes to their parents, before vowing to each other.

For instance, avatars of the same gender are not allowed to get married with one another in the MMORPGs. This principle seems to be a basic and rigid one in almost every MMORPG, with the exception of one game called Chain of Life (I) that once allowed same-sex avatars to get married, as the system had not coded the differences between marriage of same-sex avatars and that of opposite-sex avatars and thus did not restrict homosexual relationships. However, Dream of Mirror Online (the second net version of Chain of Life (I)) soon appeared and no longer supported online homosexual marriage. It seems that same-sex marriage is as big a taboo online as it is in reality in today's China.

Basically, all games encourage monogamy and offer some exclusive benefits to married avatars. In the few games that permit polygamy, where the avatars can get 
Figure 7

\section{Wedding and Honeymoon}

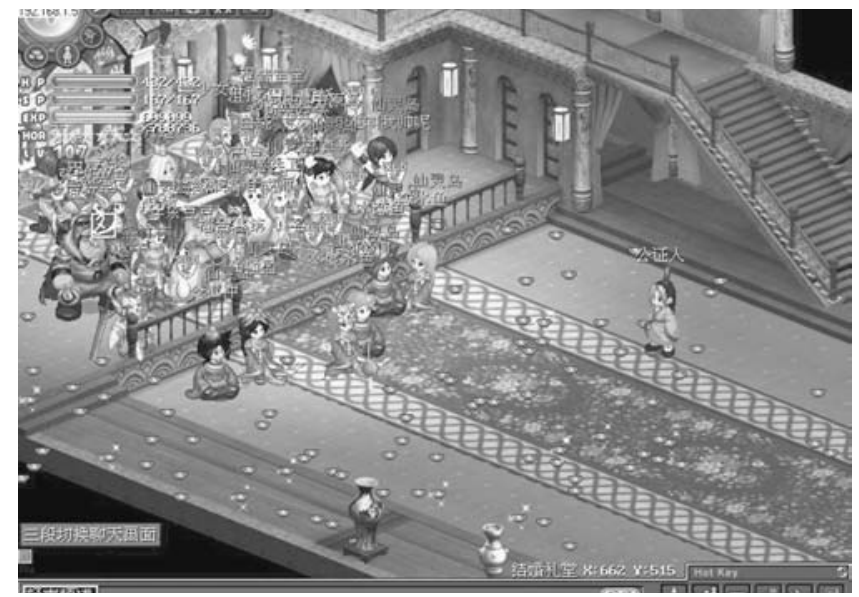

Note: The ceremony begins with sharing the gold as wedding gifts. Uploaded by Yu'er'cui (literally, Fish Wind) on March 7, 2004 from http://jinyong.jygamebbs.com.

married as many times as they want, the systems will still have some policies discriminating against avatars who get married more than once. Thus, in the games World of Qin and Dream of Mirror Online, every avatar has only one chance to experience a marriage ceremony; in the game Swordsman Online, the matchmaker (yuelao) gives rings as gifts to the avatars only on their first marriages. Sometimes the avatars cannot get married until they have climbed up into the "middle class" with a fortune, a house, and so on. Usually, the avatars should spend a lot on the wedding, as in the game Westward Journey Online (II), where one has to pay at least 100,000 in virtual money for a wedding ceremony. In the game World of Qin, the avatars pay for the wedding according to how long the ceremony lasts: If it is for 10 minutes, the avatars should pay 1,000,000 in virtual money, and if the ceremony lasts for 1 hour, they should pay 10,000,000. In the game Westward Journey Online, couples can choose different types of houses to live in after getting married, but the basic rule is that if you want a fancier house, then you will have to pay much more. An ordinary flat costs 400,000 in virtual money, whereas the VIP flat costs 5,000,000.

Another gender-biased aspect of in-game marriage is that the male avatar should take the initiative - that is, the man should be the one to propose, and the woman has the right to accept or reject the proposal. For example, Swordsman Online authorizes 


\section{Figure 8}

\section{Wedding and Honeymoon}

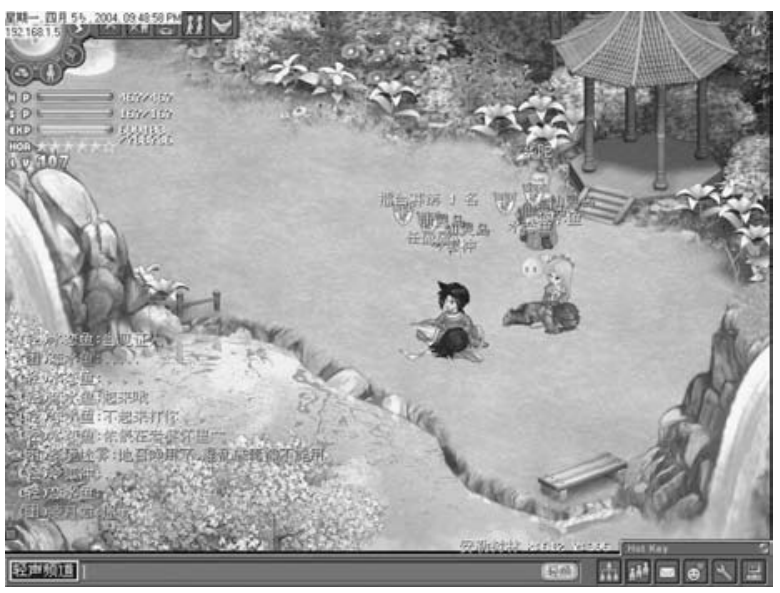

Note: After the ceremony, two of the couples perform in-game sexual activities in the garden. Uploaded by Yu'er'cui (literally, Fish Wind) on March 7, 2004 from http://jinyong.jygamebbs.com.

\section{Figure 9}

\section{Wedding and Honeymoon}

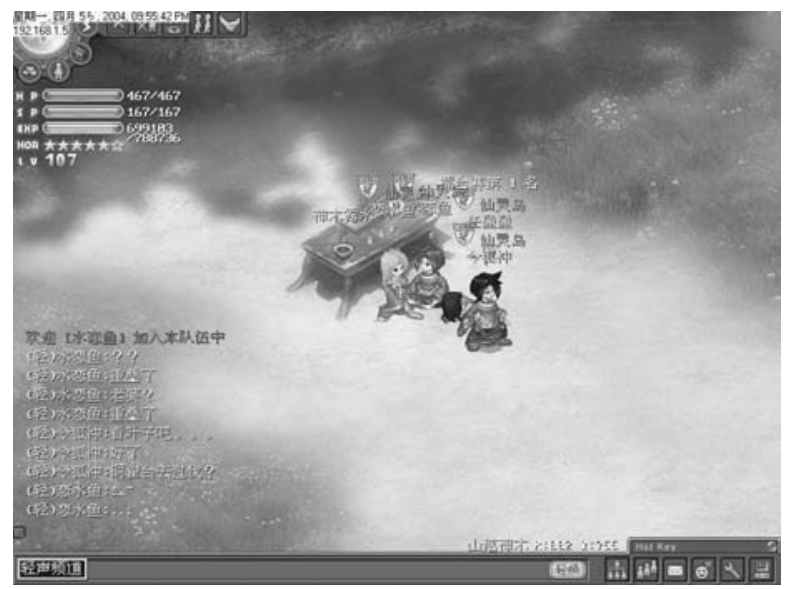

Note: One of the bridegrooms, Shuilianyu (literally, Water-loving Fish), is saying: "Darling, we are becoming one." Uploaded by Yu'er' cui (literally, Fish Wind) on March 7, 2004 from http://jinyong.jygamebbs.com. 


\section{Figure 10}

Wedding and Honeymoon

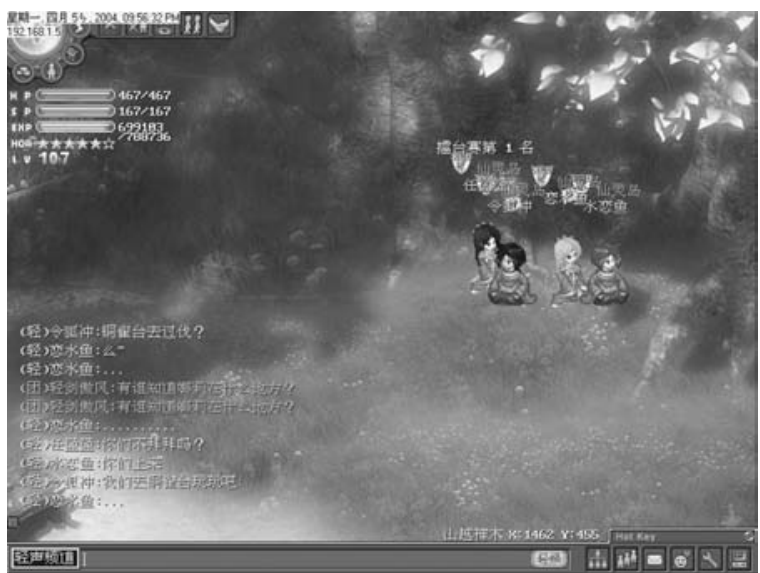

Note: These two couples are discussing whether to go to the Bronze Bird Terrace for a honeymoon trip. Uploaded by Yu'er'cui (literally, Fish Wind) on March 7, 2004 from http://jinyong.jygamebbs.com.

Figure 11 Wedding and Honeymoon

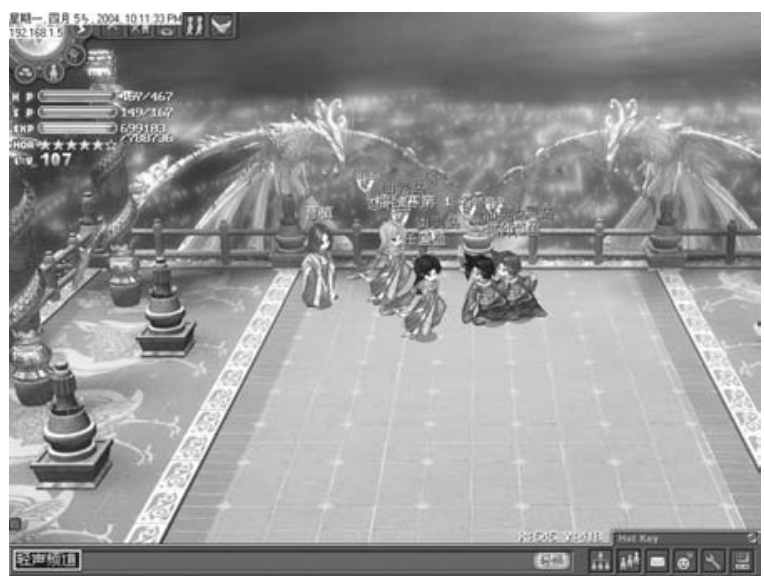

Note: Dancing on the Bronze Bird Terrace. Uploaded by Yu'er'cui (literally, Fish Wind) on March 7, 2004 from http://jinyong.jygamebbs.com. 
Figure 12

Baobao's In-Game Wedding in City of UniqueLining Up for Riding to Bride's Home

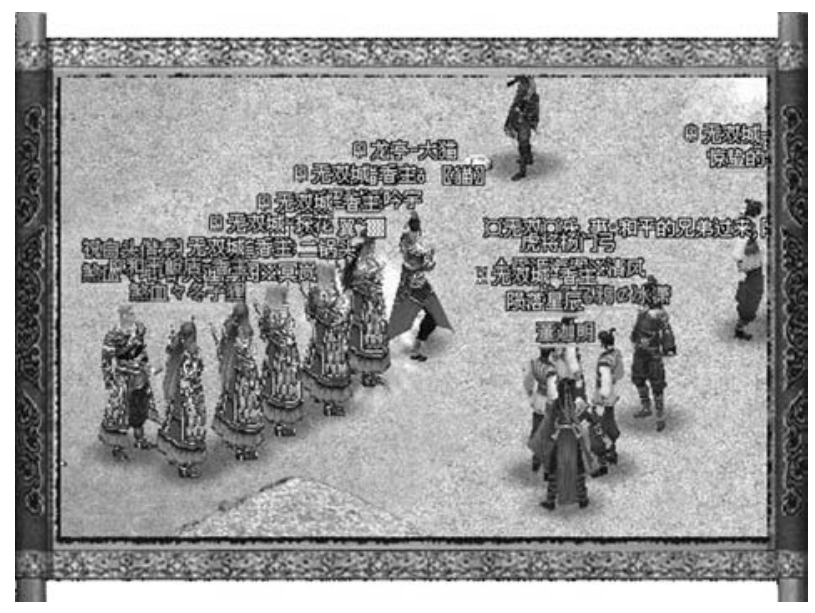

Note: These sequences of wedding images illustrate particular Chinese folk rituals, which require that bride and bridegroom should vow to Heaven and Earth, and sometimes to their parents, before vowing to each other. Uploaded by Litianzhan(literally, Slashing the Sky) on May 26, 2006 from http://show.xoyo .com, Swordsmen Online.

a matchmaker in charge of the marriages in the game. If a female avatar comes to the matchmaker and asks him to propose for her, the matchmaker will refuse and say, "It's not good for a woman to propose. You should follow the tradition and ask your future groom to come here and to initiate the proposal. It is obvious that such regulation implies a gender-stereotypical role for men and women and reinforces the conservative and normative idea that the man should be the one to take the initiativeand the woman should be passive, even in the internet entertainment marketplace.

It is noticeable that the above principles for constructing a virtual Chinese marriage in a traditional society provide, instead, a venue for young people in the urban area to marry and consume according to the ideology of material and consumer society ( $\mathrm{S}$. Li, 2004). The principles create a normative status of heterosexuality that renders any alternative sexualities "other" and marginal (Jackson, 2003). Some principles, especially the last one (i.e., that the man should take the initiative), create a world of gender-stereotypical roles that is systematically biased against women, and the formula for living everyday life in urban Chinese society in the visual game creates a world regulated by money, hierarchy, and class that may be more cruel than reality. These institutionalized regulations of heteronormativity and hierarchy are hidden not only in the skeletons of online games and computer-mediated communication 
Figure 13

\section{Baobao's In-Game Wedding in City of Unique-The Flowering Lane Made by the Bridegroom}

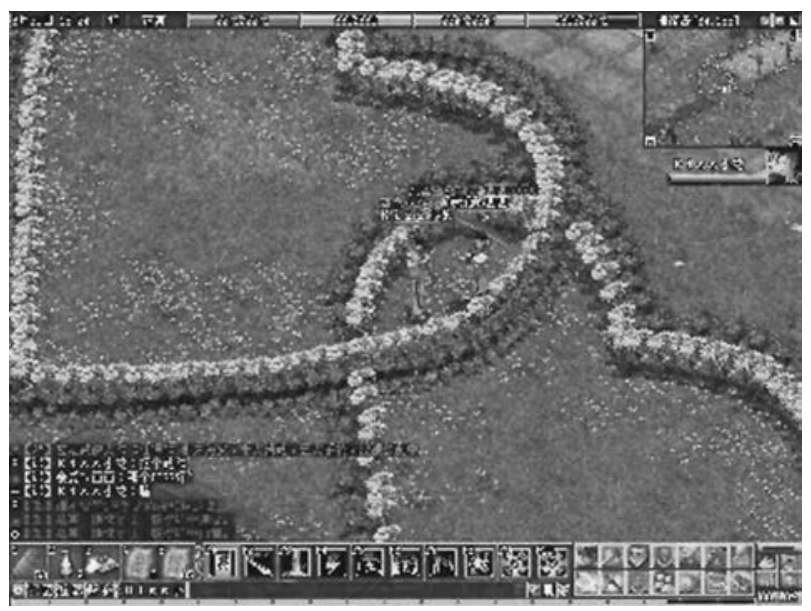

Note: Uploaded by Litianzhan (literally, Slashing the Sky) on May 26, 2006 from http://show.xoyo.com, Swordsmen Online.

but also in contemporary modern Chinese societies, which provide the backdrop for the grand narrative of in-game marriage. Jakobson and Taylor (2003) found out "how the code of game does not restrict players' actions to the heteronormative, instead creating a space of potentially subversive objects-available for use by all types of couples," because the "romantic interactions" encouraged by the gaming codes (Consalvo, 2001) support any relationship. The explicit heteronormativity of games thus is coded symbolically by the in-game storytelling.

\section{Narrated Masquerade, Subversion, and Digital Individualism}

As earlier in the article the brief history and the visualized, institutionalized, and heteronormative paradigm of in-game marriage has been documented from the heritage of text-based cyber marriage, this section will discuss how in-game marriage extends its power to the dimensions of daily life and how Chinese young people travel within the in-game marriage system to pursue friendship, love, and marriage. These players adventure in in-game relationships and interact emotionally with others, driving a striking transformation of contemporary Chinese youth subculture, breaking boundaries of gender stereotypes, and rewriting the in-game marriage as a new paradigm of computermediated relationship. 
Figure 14

Baobao's In-Game Wedding in City of Unique-Vowing to Heaven and Earth

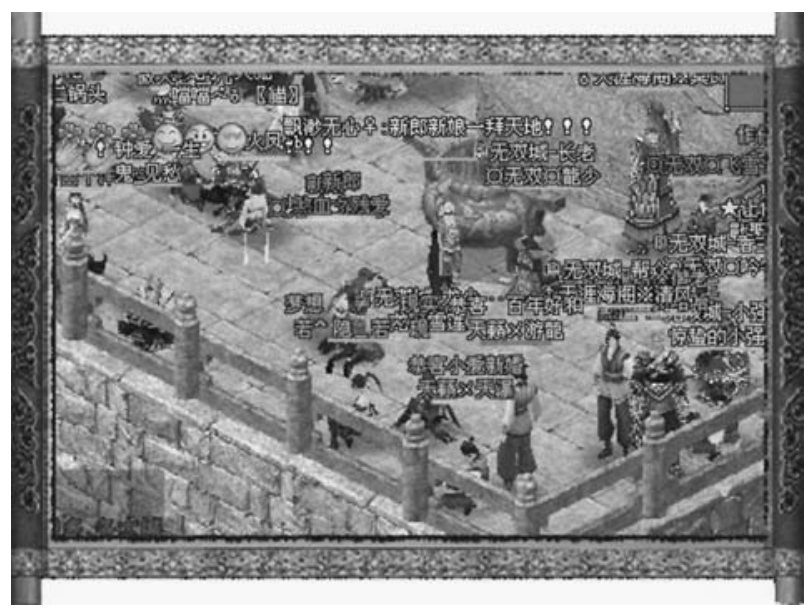

Note: Uploaded by Litianzhan (literally, Slashing the Sky) on May 26, 2006 from http://show.xoyo.com, Swordsmen Online.

\section{Figure 15}

\section{Baobao's In-Game Wedding in City of Unique- Vowing to the Mother of the Sea}

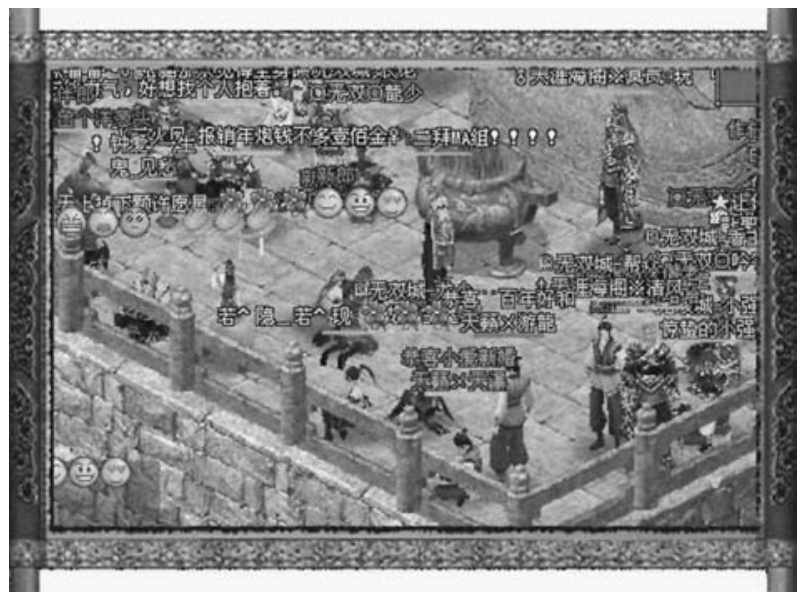

Note: Uploaded by Litianzhan (literally, Slashing the Sky) on May 26, 2006 from http://show.xoyo.com, Swordsmen Online. 
Figure 16

Baobao's In-Game Wedding in City of Unique-Vowing to Each Other

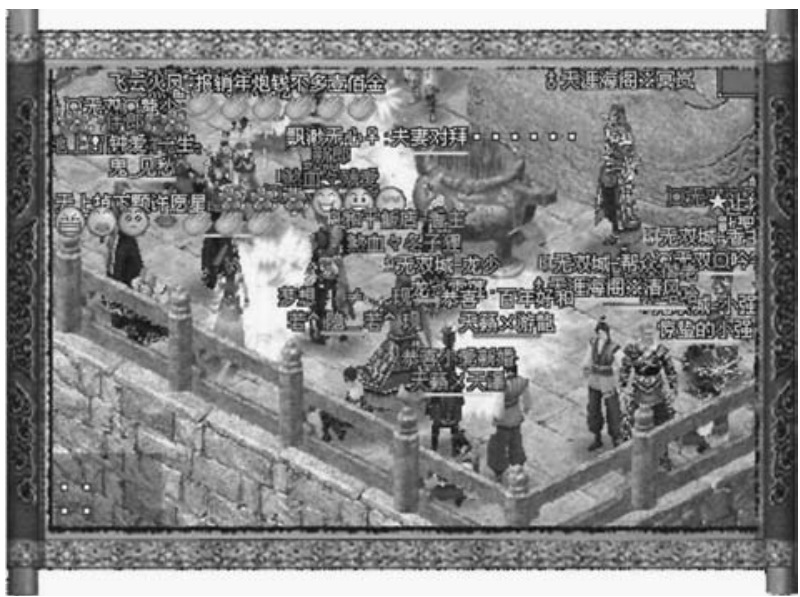

Note: Uploaded by Litianzhan (literally, Slashing the Sky) on May 26, 2006 from http://show.xoyo.com, Swordsmen Online.

\section{Figure 17}

\section{Baobao's In-Game Wedding in City of Unique-All Players Gather Around the Couple for a Wedding Picture on the Beach}

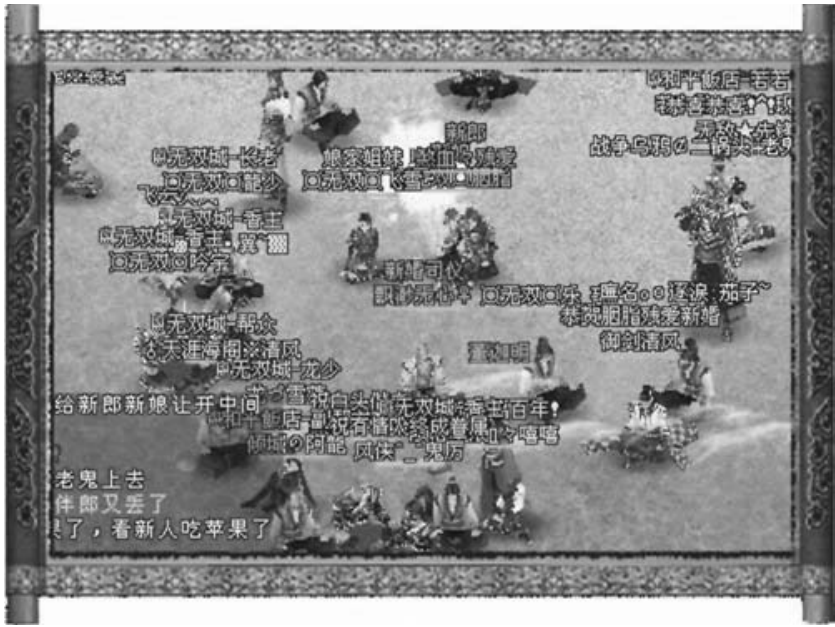

Note: Uploaded by Litianzhan (literally, Slashing the Sky) on May 26, 2006 from http://show.xoyo.com, Swordsmen Online. 


\section{Wedding Carnival}

Different people offer different reasons why these young game players are wild about having in-game marriages.

Having in-game marriage is just like eating fruit: You can survive without eating it, but everyone just likes it. (Li, F, 28)

It's just for fun, it's different from the reality, having a lot of fantasy-besides, it saves money. It's horrible to get married in reality. (Qing, F, 24)

In-game marriage is only a game; you can play and get high, but you don't need to take it seriously. (Feng, M, 23)

Just want to experience a thing that we haven't experienced before. (Hua, F, 27)

The reasons offered by these interviewees vary, but they have a common theme: "having fun." In China, marriage is still a heavy topic for many young Chinese people because of the responsibilities that go with it. Just as a game player says, "Because in real life we are all afraid to get married; but in the game, we can do something we are afraid to do and take no responsibility for it" (Feng, M, 23).

Most interviewees indicate that in-game marriage in many ways is like children "playing house," but the difference is that players are adolescents and young adults. Another difference is that the players in the games mentioned above portray the gender roles that are assigned to them and take up the associated social normativity/ materiality, whereas in MMORPGs, they experiment with marriage, try to alleviate the normativity/materiality that goes with married life and do it in the spirit of play, in a free, independent, and spontaneous spirit that demonstrates anti-utilitarianism, joyful experiences, and imagined creativities (Cao, 2005). In postsocialist China, most civilians subversively discard and revalue the spiritual and cultural burden of the puritanical conversation and the political ideology that were once deeply embedded in their lives and thoughts (S. Li, 2004; H. Zhang, 1994), and in-game marriage is one of the attempts to do this.

Zhou (2004) argued that cyber marriage may result in misunderstanding among the young game players when they downplay the responsibilities involved in marriage. This study shows that, in fact, most game players do have a clear picture of the difference between offline life and online virtual games. And for some game players, the in-game marriage has a real function: that is, to enrich their dating relationships and experience.

My boyfriend goes to college in another city. Playing the game together for us is a kind of dating. (Yun, F, 23) 
I got married once online. I established an account for my girlfriend so that we could get married there. She didn't want to play. So I played the two avatars at the same time and let them get married. (Lin, M, 23)

In reality, these two informants found it difficult to get married even though they had dated a stable boyfriend and girlfriend, respectively, for a very long time. This problem has been encountered not only by them but also by many young other people, especially those who are highly educated and living in urban society. ${ }^{10}$ Although the marriage laws stipulate that Chinese men and women can get married at the age of 22 and 20, respectively, there still are many factors that prevent them from getting married early. Usually, universities do not encourage students to get married, regardless of whether they are undergraduates or postgraduates. Workplaces always enforce the government's one-child policy and encourage their employees to get married and have babies at a late age (Tsui \& Rich, 2002). Even without these restrictions, young people still have to consider many practical problems involving money, housing, and so forth. Although getting married in reality becomes a distant or almost impossible goal in the short term, many young people find that in-game marriage is a favorable option to celebrate their dating relationships and commitments to each other.

The whole idea of in-game marriage is based on the premise that marriage is a game (Zhou, 2004). Because it is a game, players can get wild and crazy. Two other informants describe the craziest in-game wedding ceremony that they have experienced in the following paragraphs.

Once when my avatar took part in a wedding ceremony, no one expected that the enemies of the avatar groom knew its time and venue and that they'd rush into the wedding. Thus, the wedding turned into a chaotic battle. (Qian, M, 24)

I turned my wedding into a PK (player killing). I thought it would be fun, but I got killed at the end. (Bing, M, 22)

Very often, I would go to weddings just to grab red pockets (money) even if I didn't even know the bride and groom. I think that is fun! (Mei, F, 23)

In-game marriage follows the virtual marriage regulations strictly, but it sometimes ironically turns into many acquaintances' and strangers' collective carnival filled with killing, fighting, and money grabbing. In a real Chinese wedding based on tradition, there is a ritual called nao dongfang, wherein it is announced that the difficult journey of marriage begins by teasing and blessing newly married couples before their first sex after getting married. The question is, Does the crazy carnival of the in-game marriage have the appropriate anthropological elements present at the ritual of nao dongfang? Do the Chinese game players attempt to build a reinterpretation to resist social custom hidden in their gaming as well as in daily lives? These questions cannot be solved in 
this study, and in-depth research is needed to explore the cultural background of game behaviors. The most interesting event in the in-game wedding ceremony is "cracking down on counterfeit goods (dajia),"11 which especially means fighting against the conscious gender swapping of male game players.

I went to one of my friend's weddings, but he didn't get married successfully that time, because a group of avatars rushed into the banquet and began to slaughter guests, hosts, and everybody in the name of dajia. All that happened when the leader of the group shouted, "The bride is a man!" (De, F, 22)

Of course, in the game mentioned above, the bride was seen as a beautiful woman but was actually a male player disguised as a female avatar. In fact, any embodied and gendered avatar in MMORPGs may assume a fake age, gender, height, skin color, or other physical attributes; or a fake career and social status, and so forth. But dajia, in fact, only involves attacks on faked gender. Why are female avatars manipulated by male players not guilty as long as they only survive in the game space as gaming icons without getting involved in the intimate dealings of love, sex, and marriage? It is significant to explore the strong trend of homophobia on the heteronormative platform of the game, which is masked by the live show of game players' gender performativity.

\section{Masquerade and Gender Performativity}

The objections against dajia are due to renyao, ${ }^{12}$ a discriminating negative word, which literally means "human monster." The term renyao emerged from the in-game gender swapping wherein male players assume female character and enjoy playing in a hyperfeminine way, aiming at getting married to male players and even representing themselves as real women with their online friends and husbands as well. Gender swapping is one of the most debated issues in online gaming, although it somehow allows players' access to gender identities that are often socially prohibited or illegitimate offline for most Chinese people. It paradoxically conveys disembodiment of its own on the Internet and transcends reality and virtuality through challenging and penetrating the masquerade engaged with a cultural construct and features of the social structure by continually "gender doing" (West \& Zimmerman, 1987). Butler (1990) argued, "Gender proves to be performative - that is, constituting the identity it is purported to be. In this sense, gender is always a doing" (p. 25). Here, the game player's gender swapping turns into a masquerade that blurs the boundaries between "appearing" and "being" a visualized woman in cyberspace, becoming a "problematic expression and performativity" of femininity with the implication of "no fixed identities" (Bulter, 1990; Salih, 2002). The sociological interpretation of gender swapping, as Suler (2004) pointed out, is made more obscure by defining it as a social phenomenon only in relation to male players. Why are men so interested in experimenting with a 
woman's identity? ${ }^{13}$ This question embodies its own problematic, which is so commonly accepted by the general public and the gaming researches with little mention of emerged groups of female players.

It is worthy to note that the case of male avatars played by female gamers is excluded from the category of renyao and is not seen as problematic. It is possible to understand the situation if one is familiar with all the Chinese fairy tales about women who disguise themselves as men. The most popular female images are Hua Mulan and Zhu Yingtai. The former is a heroine who disguises herself as a man to serve in the army in her father's place. While serving, she is recognized as a courageous soldier and is offered a government post. The latter is a female protagonist in the Chinese story of The Butterfly Lovers (Liangzhu), who cross-dresses as a man in order to pursue formal education at a time when women were not allowed to go to school. She then falls in love with her classmate Liang. In order to resist the arranged marriage by her father, she commits suicide together with Liang, and their spirits turn into butterflies, which symbolize freedom. Like these archetypal images of Hua Mulan and Zhu Yingtai, women's gender swapping in the game space wins the favor of the general public who tend to think that their performance in cyberspace is a display of autonomy, individuality, and creativity. In contrast, male gamers involved in gender swapping are not as lucky as their female peers, and they are always despised and referred to as renyao.

Sociologically speaking, the phenomenon of renyao emerges in the situation in which more and more female game players make inroads into this once male-dominated domain (Cassell \& Jenkins, 2000), ${ }^{14}$ which breaks the original situation of both female and male avatars being manipulated by male gamers. In China, a recent report (Shanghai iResearch Co. \& 17173.com., 2005) shows that $18.78 \%$ of online game players were female at the end of May 2005, which is a small percentage but is powerful enough to challenge male users' choice to play the opposite gender online. In China, there is lack of surveys on male users' gender swapping. ${ }^{15}$ Among the 15 informants in this study, four women played female avatars and three played both male and female characters; and three men played male characters, three played both male and female characters, and one played female characters only.

Truly, the in-game marriage becomes an evocative site for a richer understanding of gender performativity of game players in contemporary China.

\section{“Superwoman," "Virtuous Woman," and Renyao}

Although three of the seven female informants refer to their experience of playing male characters online, all of them play female characters for most of their gaming time. Those who are female all the time take pride in being able to consistently play as women, as if preserving the integrity of their identity.

"I am a true girl! I hate it when people call me 'renyao"” (De, F, 22). 
This woman gamer's narrative shows a clear self-identification and emphasizes the consistency of her online and offline gender identity, defending it from being mistaken as fake. Even if these women clearly know that there is no true gender in such a Chinese game, they insist that it is better to be loyal to their own gender.

Here, there is no true gender! I have never thought to change my gender online. Beside, even if I say that I am a woman, others won't believe me 100 percent. It's just so exciting and cool to be a superwoman and so why would I bother to be a man? (Mei, F, 23)

The "superwoman" in the digital world successfully redraws a picture of the victimized woman in the image of Chinese womanhood. She is good at fighting, hence, rich and attractive in the virtual world. The "superwoman" in the Chinese context is often called iron lady (tie niangzi), who is powerful, aggressive, and assertive and therefore competent enough to compete with men. The Iron Lady invites criticism for her lack of femininity in real life, whereas the "superwoman" in the game space is challenged by whether her gender is true or not.

Many female avatars are renyao, especially those who are very good at fighting. I know many male game players like to be female avatars in the game because it is easy for women to make use of their appearance to find husbands and cheat them for virtual money and equipment. (Yun, F, 23)

This narrator is a "virtuous woman" who plays MMORPG just for online dating with her boyfriend and becomes "immersed in a fantasy environment" (Yee, 2005). These types of "virtuous women" are not good at fighting, and forming relationships is their first priority. Because in the game space the more one is good at fighting the more beautiful her appearance will be, "virtuous women" may get jealous of other female avatars' attractiveness and use the discourse that "fighting is in the domain of the men" to attack cute female avatars, which means that, because women are not good at fighting, a female avatar who is good at fighting must be an impostor (renyao). Using fighting as only one criterion to classify gender, this stereotypical discourse attacks not only the renyao but also the "superwomen." In response, one superwoman has this to say:

Now I feel it's stupid to acknowledge that I am, in fact, a woman. It's nonsense to ask me to prove myself as a woman through the web-camera. Why should I let them see my real face? I reject it always. I never ask for favor from others. I think women should be self-confident and self-respecting. (Qing, F, 24)

Turkle (1996) and Bruckman (1999) argued about how female characters are besieged by attention, sexual advances, and unrequested offers of assistance, with the assumption that they cannot do things by themselves in the context of MUD 
games. To avoid being mistaken as renyao, the "superwomen" turn down all these offers and reject being powerless women. In such games, "superwomen" are like the activists in a conventional patriarchal society trying to raise the consciousness of fighting against gender dichotomy in cyberspace, although their endeavors are often ignored by others.

In the in-game marriage market, the fairyland of game space has already formed three strong forces to compete for femininity: "virtuous woman," "superwoman," and renyao. Virtuous women use their stereotypical concept of femininity in life but fail to be the most feminine bodies online and try to form relationships in the virtual world. Superwomen create a new image of women who are assertive and aggressive, yet, although they have gorgeous bodies online, they nonetheless refuse to be gazed at and seduced. Renyao act out fictional women's gender roles, have fabulous women's body and appearance online, and are good at making use of their femininity to get whatever they want. Three types of performer use different ways to do their gender and femininity, so that the female gender and identity in the game space turns into one of diversity and fluidity, with no single modality of embodiment that stands for being a woman.

\section{To Be Renyao or Not}

Among seven male game players, three play male avatars only, and some of them express homophobia directly.

I play male avatars online only. I am a man, and I want to be a real man in the game as well as in the dream. (Jun, M, 23)

It's abnormal to be a renyao. I dislike them. If I see them, I will PK them. (Yong, M, 24)

The former statement expresses the male player's own desire not to be a renyao, and the latter does not even allow others to be renyao, showing that the strong force of homophobia has extended into the game space. Some male interviewees find it uncomfortable to acknowledge themselves as either renyao or as engaging in gender swapping online and so label their experience a way of learning differences between genders.

Maybe it is not to enjoy but just to try a different game experience brought by the other gender. (Heng, M, 25)

Indeed, for some male players, being renyao is not their choice; the most famous ID name among this group of people is "being renyao with tears" (hanlei zuo renyao). $\mathrm{He}$ feels that he is forced to assume such an identity because of certain special 
circumstances: In the world of MMORPGs, some careers belong only to women, and if men players want to play them, they have to be renyao, as the careers have been cybersocially defined on the Chinese Internet: During the game in beta-testing, there are only limited numbers of accounts and characters available, although many people want to play. In such keen competition, some male players end up becoming renyao when they get female avatar accounts. For other male players, being renyao is their active choice.

Being a renyao, the most important thing is to be happy. If you are not happy, you'd better not to be a renyao. (Feng, M, 23)

I have been playing online games for 6 years. All the avatars I play are women. Yes, I am a so-called renyao. In the past 6 years, no one has believed that I am a renyao, and no one doubts that I am not a woman in real life. (Lei, M, 20)

Some male players walked out of the closet of being renyao and shared experiences with the general public. Such is Cimeigui (literally, "thorny rose") who, on the "Netgame Special Community" hosted by pcgame.com, reviewed all strategies of playing renyao and reflected in his 5-year autobiography on being a perfect virtual woman in MMORPGs.

What do you need to do before playing female avatars in MMORPGs? The first thing is to be ready for renyao, which means you should apply for a special mailbox for such female avatars with profiles of a virtual girl's information and picture for "security reasons." Then you need to learn tricks of being renyao, research women's habits, what men need, and more importantly, the strategies. Talking with girls and remembering how they respond to your questions, noting useful information as chatting with your buddies about girls, and then developing yourself in this way. (Why do we all go online? Because we do want to find something that is desperately wanted but is difficult to get in real life. As soon as you are inspirited by such treasurable strategies of being renyao, nobody can reject the glamour.) Last, but not least, is the net-name, a catchy feminine name for boys' interest. And the action, by representing a sweet and tender woman image for you, which means you should keep your mouth shut no matter what happens. Don't be so boyish and active in chatting. (Cimeigui 2005)

For such renyao, gender is merely a "play of appearance," a style, a disguise (Butler, 1990). During the tough journey toward becoming successful woman avatars, they are capable of "parodic recitation to produce certain transgressive effects" (Lloyd, 1999, p. 197), such as having a sweet net-name and performing in a feminine way. They would ask female friends to help out in cases when their online friends ask them to talk on the phone.

The reason that renyao are criticized so much is that people feel that they have made use of the virtual identity as women in their own interest, such as getting some "money," equipment, and upgrade levels by getting help from other online male partners, and even getting married online. (Lei, M, 20) 
But a successful renyao's principle is "I never ask things from others, but people are always willing to give me what I want" (Lei, M, 20). In many ways they are like superwomen: good at fighting, beautiful, sexy, and with self-respect, the only difference being that they are better at playing the card of femininity and are proud of acting like real women and leading happy lives.

Bruckman (1999) argued that, on one hand, male players will often log on as female characters and behave suggestively, even encouraging sexual advances. On the other hand, men playing women's roles in MMORPGs have made remarks about other male players (read "male characters") expecting sexual favors in return for technical assistance. For renyao, they are just playing a game of "you wish and I will" with other men players. No matter how discriminatory the situation is for renyao, in the Chinese MMORPGs, it means more than a sexy female body to male players; actually, they are the combination of seductive female avatars and happy virtual gender swapping. They are subversive to the social norm and become the final winners in the dating and marriage market of game space. In other words, the most oppressed and devalued always turn out to be the most successful by virtue of the fact that they know best how to play the game by making use of every possible resource, including femininity.

\section{Friendship That Matters}

Chinese MMORPGs often offer many benefits for married avatars, and sometimes getting married is a way for users to upgrade their levels or improve their lives quickly.

Most game players are male. Some of them will get married even knowing very well that the other party is also a man in real life. (De, F, 22)

Getting married online does not mean falling in love. I get married online just like I find a new friend in real life. (Li, F, 28)

When upgrading levels is their first concern, in-game marriage becomes a means, not an end in itself. One female informant's story can best explain this idea of friendship.

When I met my online husband Wan for the first time, he had a wife called Nei, who is a man in real life (renyao-I am joking). When I became close with Wan and felt that I could not live without him online, Nei volunteered to get a divorce from Wan and gave me a chance to marry him online. Nei became our best friend. (De, F, 22)

In reality, this type of story seldom happens. Love is usually regarded as the basis of marriage and is always associated with exclusivity and jealousy. Friendship and generosity like this have no place. However, in-game marriage helps shake off the exclusivity and jealousy and builds up a friendship kingdom that is "pleasurable, emotional 
and affective" (Roseneil \& Budgeon, 2004, p. 139). Many game players think that "making friends" becomes the most important function of online games, and in-game marriage is regarded as the ultimate form of friendship. "I just want to know more people through playing the game. Many people emphasize the friendship" (Lei, M, 25).

Previous Chinese studies of game players criticize that players become addicted to gaming and abandon physically ties with social life (He \& Liu, 2005; Yang \& Xu, 2004). Here, we would argue that internet-based friendship is a method of communication and socialization (Jakobson \& Taylor, 2003) and that this type of digital civilization and socialization has become an indispensable part of young people's lives because of its technological impacts on social life. When asked to compare the quality of their MMOPRG friendships with their material world friendships, 39.4\% of male respondents and 53.3\% of female respondents felt that their MMORPG friends were comparable or better than their material world friends (Yee, 2005). The emotional bonding and the interaction between the game players and the virtual avatars become the key motivations for them to play the game and live their marriages online everyday. According to a recent survey, around $20.85 \%$ of game players think that making new friends via game space is better than searching or manufacturing supertreasures $(16.03 \%)$ or being master swordsmen $(11.09 \%)$. The needs of meeting each other (7.26\%) and joining holiday activities (9.29\%) in reality, and finally getting married in a game (6.11\%), become the real-life issues that Chinese game players and designers have to face (Shanghai iResearch Co. \& 17173.com., 2004). The majority of users indicated that the way they behave and interact with each other in these environments is very close to how they behave and interact with others in the material world (Yee, 2005). Because their ways of behavior and interaction online are similar with those of their real life, there is no way we can doubt the authenticity and sincerity of the online friendship.

Previous studies found that many couples married in MUD games are actually dating each other in real life (McDaniel, 1993), which is a way of extending the social relationship into the text-based game space. Although this situation also exists in China, most informants in this study state that most online couples get to know each other first through the game and then meet personally in real life. Thus, in-game marriage serves as a way of connecting the computer-mediated relationships with real life, although the directions of extension of the relationship are different, the former being a material social relationship that extends into game space, whereas the latter is a social relationship in a game that extends to real life. Facing the critique that in-game marriage is a "cool killer" (Zhou, 2004) of real marriage, one informant has a different idea.

I've been a game player for many years. According to my understanding of the Chinese Internet environment and Chinese netizens, I think that the possibility of in-game marriage turning into a real marriage is almost zero. Friendship is more rational and pervasive. (Qian, M, 24)

According to the narrative, most in-game marriages lead nowhere ${ }^{16}$ but are useful for developing friendship networks online and then extending them to offline life. The 
possibility of making it real is quite small because people have such unrealistic expectations of their online spouses that, if and when they come face-to-face, they most probably get a death blow of disappointment (Zhou, 2004). Jian guang si, which means "perish upon seeing light" (Zhou, 2004), is a Chinese term that refers to such fateful meetings. But most of the time, when the fantasy of romance has gone, the friendship stays.

In-game marriage conversely generates a vehicle to celebrate friendship, not the heteronormative relationship of the virtual world. Friendship pierces the marriage system that is masked by an imagined nostalgia and sexist gender roles. Coincidently, in relation to the trend of family and relationship in postmodern society, the present finding is consistent with that of Roseneil and Budgeon (2004), which states that friendship is regarded as more valuable than romantic love, and there is a tendency to desexualize intimacy so that it becomes more like friendship.

\section{Conclusion}

In-game marriage has become a digital metaphor for postsocialist society on the Chinese Internet and has become a unique sociocultural phenomenon. Players' exploration of visualized and institutionalized in-game marriage sheds light on the social transformation hidden in the phenomenon in contemporary China and extends to cultural expression; a mixture of a traditional cultural symbol and the new media; and the interaction between gender, sexuality, and society. This study focuses on this new social phenomenon, filling a gap in Chinese academia, as an interdisciplinary article to connect the new media, gender study, and youth subculture.

This article opened with the history of cyber marriage and further explored the rules and regulations of in-game marriage; how it constructs a symbolic world; putting together a collage of race, class, gender hierarchy, and heteronormative ideology that exists in reality and now extends into virtual narrative space, where it becomes even more materialistic and ideological than in reality. In this situation, young Chinese game players demonstrate a strong mobility, flexibility, and spirit of adventure. They are rebellious not only in the virtual world but in real life as well. Existing studies have focused on the addiction, violence, and self-isolation of game space. However, by being obsessive with a psychological perspective, we may lose sight of the force of social transformation shadowed in the young game players' practice. They deconstruct the magnificent significance of marriage, shake binary gender roles, develop multiple expressions of intimate relationships, center friendship, and question the seriousness of real life on the one side while mocking the hyperreality of the virtual game space on the other.

This article also pays a great deal of attention to the gender performativity and the male game players' gender swapping as masquerade. We classify female avatars into three types: superwoman, virtuous woman, and renyao. Each has different strategies in performing gender and femininity, bringing an intense competition into the dating 
marketing, with the renyao finally becoming the big winner. Thus, through game players' performances of visual masculinity and femininity in in-game marriages, Chinese female and male players/avatars interact with each other in various situations of everyday real/virtual lives; subvert the binary gender system; and develop relations among the individual, the digital network, individual behavior, and the consumer society. In China, the concepts of gender and sexuality are still deeply institutionalized in every aspect of daily life; however, this study demonstrates that in the game space, although these preembedded institutionalized concepts of marriage, hierarchy, and heteronormativity attempt to control avatars' lives, the only result that awaits them is failure.

The Chinese in-game marriage puts the struggles between the marginalized subject and the mainstream objects of the commercial system on the same table, combining the pursuits of modern relationships and the surrender to the hierarchy in the game's storytelling. When it demystifies the so-called legal marriage in China and shakes the dichotomy of gender roles, the in-game marriage practically provides alternative discourse for computer-mediated relationships that represent the new generation's confusion and happiness in seeking the possibilities of constructing new relationships and new forms of love based on the platform of new media.

\section{Notes}

1. Wanghun has also been translated into English as "Internet marriage," "online marriage," and "marriage on the Internet." It appeared in the Guang Ming Daily on January 19, 2001, then reappeared in the Renmin Daily on April 20, 2005. Wanghun first entered the official mainstream media, then was added in the "New Words Supplement" of Lexicographical Studies. It is argued that the term symbolizes a new concept in computer-mediated relationship.

2. More and more Chinese public media have been involved in the mania stirred by this influential cyber marriage during the past 3 years, and two recent reports broadcast on China Central Television somewhat officially denounced such Internet-relayed gamelike marriage on July 27 and July 29, 2006. For details, see China Central Television, "When Marriage Becomes Cyber Activity," Law Online (Fazhi zaixian), July 27, 2006; China Central Television. "The Boy's Experiences of 30 Cyber Marriages," Thirty-minute News (Xinwen sanshifen), July 29, 2006.

3. QQ, owned by Tencent Inc., may be the most popular free instant messaging computer program in Mainland China. QQ features include a chatroom, games, personal avatars, Internet shortage.

4. The recent 18th Statistical Survey Report on Internet Development in China shows that the total of Internet users has increased to 123.00 million. The $95 \%$ confidence intervals for the estimate were 116.50 million to 129.50 million. The services of online games were most frequently used by more than $31.8 \%$ of Chinese Internet users in July 2006.

5. These numbers are increasing everyday. By August 28, 2006, there were 43,181 registered users, 18,408 albums, and 114,581 images.

6. The Top 10 domestic massively multiplayer online role playing games (MMOPRGs) in 2004 include the following: Swordsman Online (Jianxia qingyuan, http://jx.xoyo.com/); Fantasy Westward Journey (Menghuan xiyou, http://xyq.163.com/); Westward Journey Online II (Dahua xiyou 2, http://xy2.163.com/); Monster \& Me (Huanling youxia, http://hlyx.91.com/); M2 China Online (Shenjia qibing, http://www .m2china.com.cn/); World of Qin (Tian jiao, http://www.linuxgoo.com); Chain of Life (Xuanyuan jian, http://swdol.joypark.com.cn); Conquer (Zhenfu, http://zf.91.com/home.htm); Meteor, Butterfly and a Blade (Liuxing hudie jian, http://www.mbs.com.cn/); and NetDream (Mengxiang, http://www.netdream.com.cn/).

7. Text-based cyber marriage usually happens in chatrooms in cyberspace, free of charge, whereas MMORPGs players usually need to pay a monthly subscription fee of around US $\$ 10$ to $\$ 15$, thereby 
making the environment of in-game marriage comparatively smaller than that of text-based cyber marriage in Internet Relay Chat (IRC) or virtual communities.

8. The first sexual revolution in P.R. China was after the establishment of "New China"; in fact, it should be called a prohibition rather than a revolution, as for nearly 30 years the only privileged function of sex was for reproduction. The second sexual revolution saw that sex was not only for reproduction but for pleasure and desire as well, after the opening up. The third happened in the late 1990s, which emphasized sex as a human right.

9. According to the Intermediate People's Court of Nanjing, Jiangsu Province, the first divorce case due to cyber marriage was filed in 2001. Since then, the numbers have continued to increase: In 2002, there were 20 cases reported; in 2003, there were 80; and in the first five months of 2004, there were 151. In Guangzhou, the Information Times reported that $30 \%$ of legal marriage dissensions were caused by cyber marriage (Yuan \& Sivelle, 2005).

10. The situation of marriage in rural areas is quite different.

11. Dajia could be identified as an ideological movement stirred by the postsocialist market economy. The "Office of Dajia" officially has been launched nationwide in response to the cases of fake products. By now, dajia has also been used to describe the anti-academic-cheating movement.

12. This Chinese term originally referred to the trans-gender persons of Thailand.

13. Suler (2004) offered some hypotheses for explaining the emergence of gender swapping, such as "in some online games where participants assume imaginary identities (e.g., Multi-User Dungeon or Dimension [MUDs]), being a female may be advantageous"; "A male looking for intimacy, romance, and/or cybersex from another male may be acting upon conscious or unconscious homosexual feelings"; and "in rare cases, gender-switching could be a sign of what would be diagnosed as 'gender confusion'-that is, a psychological disturbance where one's identity as a male or female has not fully developed." For more details, see "Do Boys (and Girls) Just Wanna Have Fun? Gender Switching in Cyberspace."

14. Recent research suggests that more than $40 \%$ of U.S. gamers are female and that the overall online gender split is approximately 50/50.

15. Kathryn Wright (2000) conducted a small online survey that focused on male users' gender swapping within a sample of 33 male game players. It found that $6 \%$ of the participants played female characters for $25 \%$ or less of their gaming time, $24 \%$ played female characters for $26 \%$ to $50 \%$ of their gaming time, $15 \%$ played female characters for $51 \%$ to $75 \%$ of their gaming time, and $42 \%$ played female characters for $76 \%$ to $100 \%$ of their gaming time, whereas $12 \%$ avoided answering this question. For detail, see Genderbending in Games on http://www.womengamers.com/doctork/gender.php.

16. However, several recent cases in China have highlighted the potentially general acceptance of cyber wedding and in-game marriage. For instance, 17131.com reports that three couples finally succeeded in "real marriage" after long histories of in-game marriage when playing JinYong Swordsman Online. The BBS manager Jin Lingzhi uploaded wedding photography on bbs.17173.com on October 17,2006 in memory of a moment of interaction between online and offline relationships. (Retrieved October 20, 2006, from http://bbs.17173.com/topics/3105/200610/17/1811271,1.html.) Qingdao Morning even propagandizes one cyber marriage took place between a couple in a long-distance relationship on May 20, 2005. The wedding, officially authorized by government agencies, was hosted both in Qingdao City and at research vessel "Dayang No.1." It also was represented online spontaneously at www.qingdaonews.com following the traditional marriage ritual by demonstrating game-like interactive image sequences. (Retrieved 20 July, 2006, from http://www.qingdaonews.com/content/2005-05/20/content_4730681.htm.)

\section{References}

Bakardjieva, M., \& Smith, R. (2001). The Internet in everydaylife. New Media \& Society, 3(1), 67-83.

Bargh, J. A. (2002). Beyond simple truths: The human-Internet interaction. Journal of Social Issues, 58(1), 1-8.

Bruckman, A. S. (1999). Gender swapping on the Internet. In V. J. Vitanza (Ed.), Cyberreader (2nd ed., pp. 418-425). Boston: Allyn \& Bacon. 
Bryce, J., \& Rutter, J. (2003). The gendering of computer gaming: Experiences and space. In S. Fleming \& I. Jones (Eds.), Leisure culture: Investigations in sport, media and technology (pp. 3-22). Eastbourne, UK: Leisure Studies Association.

Butler, J. (1990). Gender trouble: Feminism and the subversion of identity. New York: Routledge.

Cao, H. (2005, March 7). When love encounters the spirit of play. News Weekly, 63.

Cassell, J., \& Jenkins, H. (2000). From Barbie to mortal combat: Gender and computer games. Cambridge, MA: MIT Press.

Chen, W. (2004, September 8). The present condition and the trend of development about Chinese online game industry. Paper presented at the 2nd annual conference of Chinese online game, Beijing, P.R. China.

Cherny, L. (1999). Conversation and community: Chat in a virtual world. Stanford, CA: CSLI Publications.

China Internet Network Information Center (CNNIC). (2005). The 15th statistical survey report on the Internet development in China. Beijing, China: Author

Cimeigui. (2005). Make a extremely perfect Renyao. Retrieved 30 January, 2005, from http://www .pcgames.com.cn/netgames/zhuanti/mu/xinde/0501/552587.html

Consalvo, M. (2001, April). Hot dates and fairy-tale romances: Studying sexuality in videogames. Paper presented at Playing with the Future, Manchester, UK.

Dai, X., \& Li, C. (2004). Cyber marriage: Game or trap? Community, 3-5, 61.

Danet, B. (1996, February). Text as mask: Gender and identity on the Internet. Paper presented at the conference on "Masquerade and Gendered Identity," Venice, Italy. Retrieved from http://atar.mscc.huji .ac.il/ msdanet/mask.html

DiMaggion, P., Hargittai, E., Neuman, W. R., \& Robinson, J. P. (2001). Social implications of the Internet. Annual Review of Sociology, 2001(27), 307-336.

Ducheneaut, N., \& Moore, R. J. (2004, November 6-10). The social side of gaming: A study of interaction patterns in a massively multiplayer online game. Paper presented at the the ACM Conference on Computer-Supported Cooperative Work (CSCW 2004), Chicago.

Fang, G. (2004). Cyber marriage encounters the legal vacuum. The Western, 7, 35-36.

Feng, X. (2004). Cyber marriage: Virtual love or killer of reality? Youth Reference, 3.

Graddol, D., \& Swann, J. (1989). Gender voices. Oxford, UK: Basil Blackwell.

He, H., \& Liu, H. (2005). Internet love of the married group and role conflict. Journal of South-Central University for Nationalities (Humanities and Social Science), 25(2), 131-135.

Howard, P. N., \& Jones, S. (2004). Society online: The Internet in context. Thousand Oaks, CA: Sage.

Huang, X. (2002, August 26). New revolution, sex revolution. News Weekly, pp. 24-27.

Jackson, S. (2003). Heterosexuality, heteronormativity and gender hierarchy: Some reflection on recent debates. In J. Weeks, J. Holland, \& M. Waites (Eds.), Sexualities and society: A reader (pp. 69-83). Cambridge, UK: Polity.

Jakobson, M., \& Taylor, T. L. (2003, May). The Sopranos meets EverQuest: Social networking in massively multiplayer online games. Paper presented at the 5th International Digital Arts and Culture Conference, Melbourne, Australia.

Jiang, Y. (2005). "Net marriage" and marriage contract theory. Journal of BUPT (Social Science), 7(1), 62-65.

Kücklich, J. (2003). Perspectives of computer game philology. Game Studies: The International Journal of Computer Game Research, 3(1). Retrieved from http://www.gamestudies.org/0301/kucklich/

Li, H. (2004). Self-identity crisis in the cyber/virtual communication. Social Science, 26(6), 84-88.

Li, S. (2004). Game spirit and consumerism: Review of Chinese new-sharp magazines. Journal of China University of Mining \& Technology (Social Science), 6(3), 120-124.

Liu, C. (2002). New words supplement: Marriage on the Internet. Lexicographical Studies, 24(7), 155.

Lloyd, M. (1999). Performativity, parody, politics. Theory, Culture \& Society, 16, 195-213.

Lu, L. (2004, November). Cyber marriage: Pioneering or gaming? Mental World, 97, 4-6.

McDaniel, H., III. (1993). Marriage: Encyclopcedia of muds. Retrieved 18 January, 2005, from http://www.iowa mug.net/muddic/dic/M.html\#MARRIAGE 
Roseneil, S., \& Budgeon, S. (2004). Culture of intimacy and care beyond "the family": Personal life and social change in the early 21 st century. Current Sociology, 52(2), 135-159.

Salih, S. (2002). Judith Butler. London and New York: Routledge.

Shanghai iResearch Co., L., \& 17173.com. (2005). The 5th online-game research report. Shanghai: Author.

Suler, J. (2004). Do boys (and girls) just wanna have fun? Gender switching in cyberspace. In A. Kunkel (Eds.), Gender communication (pp. 149-152). Dubuque, IA: Kendall/Hunt.

Tsui, M., \& Rich, L. (2002). The only child and educational opportunity for girls in urban China. Gender \& Society, 16(1), 74-92.

Turkle, S. (1996). Life on the screen: Identity in the age of the Internet. London: Weidenfeld \& Nicolson. Wang, X., \& Gao, X. (2004). How to understand the phenomenon of cyber marriage. The Western, 7, 37-38.

Wellman, B., \& Haythornthwaite, C. A. (2002). The Internet in everyday life. Malden, MA and Oxford, UK: Blackwell.

West, C., \& Zimmerman, D. H. (1987). Doing gender. Gender \& Society, 1(2), 125-151.

Wright, K. (2000). Gender-bending in games on http://www.womengamers.com/doctork/gender.php.

Xu, L., \& Tian, X. (2005). On the development of Internet game industries. Journal of China Youth College for Political Science, 24(2), 114-119.

Yang, H., \& Xu, H. (2004). The disassimilation of digital game and social countermeasure. Journal of Inner Mongolia Agricultural University (Social Science Edition), 6(21), 121-123.

Yee, N. (2005). The psychology of massively multi-users online role-playing games: Motivations, emotional investment, relationships and problem usage. In R. Schroder \& A. Axelsson (Eds.), Avatars at work and play: Collaboration and interaction in shared virtual environments. London: Springer-Verlag.

Yuan, R., \& Sivelle, K. (2005). On-line marriage can be a mixed blessing. Retrieved 18 June, 2005, from http://www.chinadaily.com.cn/english/doc/2005-06/07/content_449284.htm

Zhang, H. (1994). Contemporary myth: The spiritual core of urban pop culture. Journal of Shanghai University (Social Science Edition), 11(5), 25-29.

Zhang, J. (2005). Policy suggestion to developing online game in China. Science and China Youth and Technology, pp. 48-49.

Zhen, S. (2005). Limitation and its strategies against Continued development of China's online game Industries. High-Technology and Industrialization, 12(5), 29-31.

Zhen, Z. (2001, April 30). Cyber marriage: Reality or fantasy? China Woman, p. 4.

Zhou, R. (2004, March 20). Marriage bells toll in cyber churches. China Daily (North American ed.), p. 3.

Weihua Wu is a postdoctoral fellow in the International Center for Advanced Studies at New York University. His research interests include Chinese animation, visual culture, and Internet ethnography.

Steve Fore is an associate professor in the School of Creative Media at the City University of Hong Kong, where he teaches classes in animation studies, new media theory, documentary, culture and technology, and whatever else the cat drags in.

Xiying Wang is a PhD candidate in the Department of Social Work and Social Administration at the University of Hong Kong. Her current research interests include dating violence, gender study, and Chinese feminism.

Petula Sik Ying Ho is an associate professor in the Department of Social Work and Social Administration at the University of Hong Kong. She teaches human sexuality, body politics, social work methods, and qualitative research. 